\title{
Introduction to the Leadership Forum 2015: A decisive year for development?
}

The Millennium Development Goals (MDGs) mean many things to many people. Public debates have recognized the critical role they played in helping the topic of development, the related struggle against poverty and its environmental implications to emerge in the collective consciousness of global actors. In fact, diminishing the number of people living in extreme poverty by half, the main priority of the MDGs, is the most notable success of this political process that began with the Millennium Development Summit in 2000. At the same time, the MDGs have been heavily criticized by leaders and academics for being indicator-driven and, in some cases, unrealistic. It still seems that five of the eight MDGs will not be met before the goals expire in 2015 .

The year 2015 should also represent a time for reflection about discussions related to international development. While global leaders discuss the tangible advances and challenges that have emerged in relation to the MDGs, citizens have been encouraged by the United Nations to give their input through "The World We Want" campaign.

This is also the European Year for Development. As the largest donor in the world, the European Union (EU) has dedicated 2015 to public discussions on this subject. This campaign aims to inform European citizens about EU development activities and stimulate their interest in development cooperation.

In recognition of the importance that 2015 should play in global development discussions, Regions $\mathcal{E}$ Cohesion asks: "Will 2015 truly be a decisive year for development?" The discussions surrounding the post-2015 agenda not only address the goals and indicators related to the MDG program but also question the very meaning of development. Will advanced industrial states promote transformative development that aims to establish more equitable and sustainable global practices in terms of economic markets, social transformations and the use of natural resources? Will unequal development relationships between "North" and "South" finally be transformed into transnational partnerships between interactive regions? 
What roles can/should regional organizations play in the post-2015 global development program?

Given the highly salient nature of these debates, Regions $\mathcal{E}$ Cohesion will dedicate significant attention in its Leadership Forum throughout 2015 to the subject of international development. To open this reflection, we are pleased to publish in this issue the Kapuscinski Lecture/Keynote Address of the 2014 RISC Consortium Conference delivered by Jens Martens, Executive Director of the Global Policy Forum on the subject of "Universal Development." The RISC Consortium thanks the United Nations Development Program and the European Commission, the institutions that sponsor the Kapuscinski Lecture Series and the University of Helsinki, which organized the event. The second article in this issue's Leadership Forum is a contribution from Gibran Cervantes, an entrepreneur dedicated to sustainable development, on the importance of holistic education in social cohesion and sustainability processes in local communities. By presenting these contributions side by side, we are pleased to offer readings that juxtapose local and global visions of development. These articles present reflections that relate, on one hand, to macro political debates related to global affairs and, on the other, to community-based initiatives aimed at promoting social change from below.

The Editors 